\title{
Oligoclonal T Cell Receptor Gene Rearrangements in Blood Lymphocytes of Patients with Acute Epstein-Barr Virus-induced Infectious Mononucleosis
}

\author{
John G. Strickler, ${ }^{\star}$ Lucile A. Movahed, ${ }^{8}$ Kazimiera J. Gajl-Peczalska, ${ }^{*}$ Charles A. Horwitz, ${ }^{\ddagger}$ \\ Richard D. Brunning, " and Lawrence M. Weiss" \\ *Departments of Pathology, University of Minnesota Hospital, Minneapolis, Minnesota 55455; ${ }^{\ddagger}$ Metropolitan-Mount Sinai \\ Medical Center, Minneapolis, Minnesota 55404; ${ }^{\circledR}$ Stanford University Medical Center, Stanford, California 94305 ; \\ and "City of Hope Medical Center, Duarte, California 91010-0269
}

\begin{abstract}
Gene rearrangement studies were performed on blood lymphocytes from eight patients with acute Epstein-Barr virus-induced infectious mononucleosis. The diagnosis in each case was based on characteristic clinical, hematologic, and serologic findings. The blood lymphocytes in each patient consisted predominantly of CD8 + T cells. EBV DNA was detected in seven patients by Southern blot analysis (EBV Bam HI W probe, Bam HI). A germline configuration was found for the immunoglobulin heavy and light chain genes $\left(\mathrm{J}_{\mathrm{H}}\right.$ probe, Bam $\mathrm{HI}$ and Eco RI; $C_{\kappa}$ probe, Bam HI; and $C_{\lambda}$ probe, Eco $\left.R I\right)$. T cell receptor gene rearrangements were detected with $J_{\gamma}$ and $J_{\beta 1+2}$ probes. Using a $J_{\gamma}$ probe with two different restriction enzymes (Bgl II and Eco RI), the blood from each patient showed several bands corresponding to the polyclonal pattern previously described in the blood of normal individuals. Using $\mathbf{J}_{\beta 1+2}$ probes with two different restriction enzymes (Bgl II and Bam HI), each case showed from 3 to about 12 extragermline bands of varying intensity and in different locations from case to case. In addition, each case showed relative deletion of the $J_{\beta 1}$ germline band. This oligoclonal pattern of $T$ cell receptor gene rearrangements has not been previously reported in benign or malignant T cell populations. (J. Clin. Invest. 1990. 86:13581363). Key words: Southern blot $\bullet$ clonality $\bullet$ CD8 + T cells $\bullet$ immunophenotype $\bullet$ immunogenotype
\end{abstract}

\section{Introduction}

Within the last five years, the configuration of the $T C R^{1}$ gene has been used as a marker of clonality in $\mathrm{T}$ cell populations (1-9). Generally, the presence of one or two extragermline

Address reprint requests to Dr. Lawrence Weiss, 2241 Anatomic Pathology, City of Hope National Medical Center, 1500 East Duarte Road, Duarte, CA 91010-0269.

Received for publication 20 April 1990 and in revised form 15 June 1990.

1. Abbreviations used in this paper: EBNA, EBV-associated nuclear antigens; EBV-IM, EBV-induced infectious mononucleosis; TCR, T cell receptor; VCA, EBV-specific viral capsid antigens.

J. Clin. Invest.

(C) The American Society for Clinical Investigation, Inc.

$0021-9738 / 90 / 10 / 1358 / 06 \$ 2.00$

Volume 86, October 1990, 1358-1363 bands on an appropriate Southern blot analysis has proved to be an effective indicator of a malignant $T$ cell population, while benign $T$ cell populations have usually demonstrated a germline configuration, often with relative or absolute deletion of the germline band from the $\beta 1$ locus. There are exceptions to this rule; for example, clonal populations have been observed in two indolent dermatologic disorders, lymphomatoid papulosis and pityriasis lichenoides et varioliformis acuta, that may represent low-grade $T$ cell malignancies rather than truly benign $T$ cell disorders (10-12).

Acute EBV-IM is usually considered to be a benign, selflimited disease caused by a primary Epstein-Barr virus infection. It is thought to begin with a productive EBV infection of the oropharyngeal epithelium (13). The virus reaches Waldeyer's ring by way of the epithelium, where infection and transformation of B lymphocytes occurs (13-15). The transformed B lymphocytes proliferate locally and may briefly enter the blood during the initial stages of the infection, but the number of EBV-infected B cells is usually less than $0.05 \%$ of blood mononuclear cells (16). Most of the atypical lymphocytes in the blood of EBV-IM patients are actually T cells, which are thought to be primarily responsible for limiting and controlling the EBV infection. For example, T lymphocytes from EBV-IM patients have been shown to delay outgrowth of autologous EBV-infected B lymphocytes (17) and to inhibit outgrowth of EBV-transformed human fetal lymphocytes (18).

In this report, we have investigated the possibility that clonal TCR gene rearrangements may be found in acute EBVIM. Immunophenotypic and immunogenotypic studies of blood lymphocytes from eight patients with acute EBV-IM are described. Our analysis confirms previous studies suggesting that these lymphocytes are predominantly CD8+ T cells (19). Moreover, we report that these $\mathrm{T}$ cells have a unique oligoclonal TCR genotype, a pattern of clonality that has not previously been described in lymphoid tissues.

\section{Methods}

Case selection. The investigation was performed after approval by the Committee on the Use of Human Subjects in Research at the University of Minnesota. Eight patients who had characteristic clinical, hematologic, and serologic findings of acute EBV-IM were chosen for study. All patients were male students (ages 18-22) at the University of Minnesota with clinical symptoms typical of acute EBV-IM, including fever, sore throat, and lymphadenopathy. The diagnosis in each patient was confirmed by standard serologic methods (see Results) $(20-23)$. None of the patients had a history of inherited or acquired immunodeficiency. 
Table I. Pertinent Laboratory Data from Eight Patients with Acute Epstein-Barr Virus-induced Infectious Mononucleosis

\begin{tabular}{|c|c|c|c|c|c|c|}
\hline Case & $\mathrm{WBC} \times 10^{9} / \mathrm{L}$ & $\begin{array}{c}\text { Lymphocytes } \\
\text { in differential } \\
\text { count } \\
\text { (atypicals)* }\end{array}$ & $\begin{array}{l}\text { Heterophil } \\
\text { antibodies } \\
\text { (horse cells) }\end{array}$ & VCA-IgM & VCA-IgG & EBNA \\
\hline & & \% & & & & \\
\hline 1 & 7.7 & $88(85)$ & $1: 448$ & $\geq 1: 160$ & $1: 80$ & $<1: 2$ \\
\hline 2 & 11.0 & $52(45)$ & $1: 4336$ & $\geq 1: 160$ & $1: 160-1: 320$ & $<1: 2$ \\
\hline 3 & 16.6 & $74(38)$ & $1: 224$ & $1: 80-1: 160$ & $1: 320$ & $<1: 2$ \\
\hline 4 & 23.0 & $83(36)$ & $1: 224$ & $1: 10-1: 20$ & $1: 640$ & $<1: 2$ \\
\hline 5 & 8.5 & $78(55)$ & $1: 224$ & $1: 160-1: 320$ & $1: 320$ & $<1: 2$ \\
\hline 6 & 24.5 & $78(65)$ & $1: 224$ & $1: 160$ & $1: 320-1: 640$ & $<1.2$ \\
\hline 7 & 6.3 & $54(18)$ & $1: 448$ & $\geq 1: 160$ & 1:160 & $<1: 2$ \\
\hline 8 & 12.4 & $52(17)$ & $1: 448$ & $1: 160$ & $1: 640$ & $<1: 2$ \\
\hline
\end{tabular}

* Number in parentheses refers to the number of atypical lymphocytes per 100 white blood cells. ${ }^{\ddagger}$ Monospot tests (Ortho Diagnostic) were also positive in each case.

Immunophenotype studies. The blood lymphocytes from each case were evaluated using immunologic marker studies and flow cytometry, as previously described (24). A panel of B- and T-lymphocyte-associated monoclonal antibodies was applied, including the pan-B cell antibody B43 (CD19; Fatih Uckun, University of Minnesota), the pan-T antibodies 13B3 (CD2; Dan Vallera, University of Minnesota) T3 (CD3; Coulter Immunology, Hialeah, FL), T101 (CD5; Dan Vallera), and G3.7 (CD7; Dan Vallera), the helper T cell antibody antiLeu 3 (CD4; Becton Dickinson, Mountain View, CA), and the cytotoxic/suppressor T cell antibody T8 (CD8; Ortho Diagnostic Systems, Inc., Raritan, $\mathrm{NJ}$ ).

Immunogenotype studies. DNA from blood lymphocytes, which had been isolated using Ficoll-Hypaque density gradient centrifugation, was extracted and purified according to standard procedures (25). $10 \mu \mathrm{g}$ of DNA was digested with an appropriate restriction enzyme, and the resulting fragments were separated by gel electrophoresis in $0.8 \%$ agarose gel. Separated DNA fragments were then transferred from the gels onto activated nylon membranes (Genatran-45; Plasco, Woburn, MA) by the transfer method of Southern (26). Membranes were then hybridized with DNA probe fragments that had been ${ }^{32} \mathrm{P}$-labeled by the random oligonucleotide priming technique (27). Details of the methods of hybridization and autoradiography have been previously described (25). DNA probe fragments used included the joining region of the Ig heavy chain gene, the constant regions of the kappa and lambda Ig light chain genes (25), the joining region of the gamma TCR gene (11), and the joining regions of the beta TCR gene (12). Restriction enzymes were purchased from New England Biolabs, Beverly, MA.
Detection of Epstein-Barr virus. Southern blot hybridization studies were performed as described elsewhere, $(25,26)$ using $10 \mu \mathrm{g}$ of purified DNA digested by Bam HI. The resulting fragments were electrophoretically fractionated according to size and transferred onto activated nylon membranes. Hybridization was performed with two separate EBV probe fragments that had been ${ }^{32} \mathrm{P}$-labeled by the random oligonucleotide priming technique (27). One probe consisted of a Bam HI W fragment of EBV DNA (28), and the other probe was a 5.2-kb Bam HI-Eco RI restriction fragment containing the $500 \mathrm{bp}$ tandem terminal repeated sequence of the EBV genome (29).

\section{Results}

Hematologic and serologic diagnostic studies are summarized in Table I. The absolute white blood cell count was normal in three patients, and a leukocytosis up to $23 \times 10^{9} / \mathrm{L}$ was present in five cases. All cases had $>50 \%$ lymphocytes and at least $10 \%$ atypical forms in the differential count. The heterophil titer was 1:224 or greater in all patients. In addition, Monospot tests (Ortho Diagnostic) were positive in each case. EBV profiles from all patients were diagnostic of primary EBV infections, based on positive anti-VCA IgM and IgG responses and negative $(<1: 2)$ anti-EBNA titers.

The immunophenotype studies are summarized in Table II. The blood lymphocytes in each patient consisted predominantly of $T$ cells, with B cells comprising $2 \%$ or less of the

Table II. Summary of Immunophenotype Studies

\begin{tabular}{|c|c|c|c|c|c|c|c|c|}
\hline & Case 1 & Case 2 & Case 3 & Case 4 & Case 5 & Case 6 & Case 7 & Case 8 \\
\hline CD19 & 2 & 7 & 2 & 1 & 1 & 1 & 1 & 2 \\
\hline $\mathrm{CD} 2$ & 96 & 90 & 96 & 83 & 94 & 98 & 92 & 92 \\
\hline CD3 & 89 & 78 & 90 & 77 & 70 & 94 & 79 & 80 \\
\hline CD5 & 85 & 82 & 91 & 72 & 58 & 88 & 76 & 71 \\
\hline CD7 & 35 & 78 & 94 & 55 & 61 & ND & 29 & 61 \\
\hline CD4 & 13 & 32 & 10 & 15 & 12 & 8 & 24 & 22 \\
\hline CD8 & 76 & 37 & 83 & 57 & 54 & 75 & 65 & 50 \\
\hline CD4:CD8 ratio & 0.17 & 0.86 & 0.12 & 0.26 & 0.22 & 0.11 & 0.37 & 0.44 \\
\hline
\end{tabular}

ND, not done. 


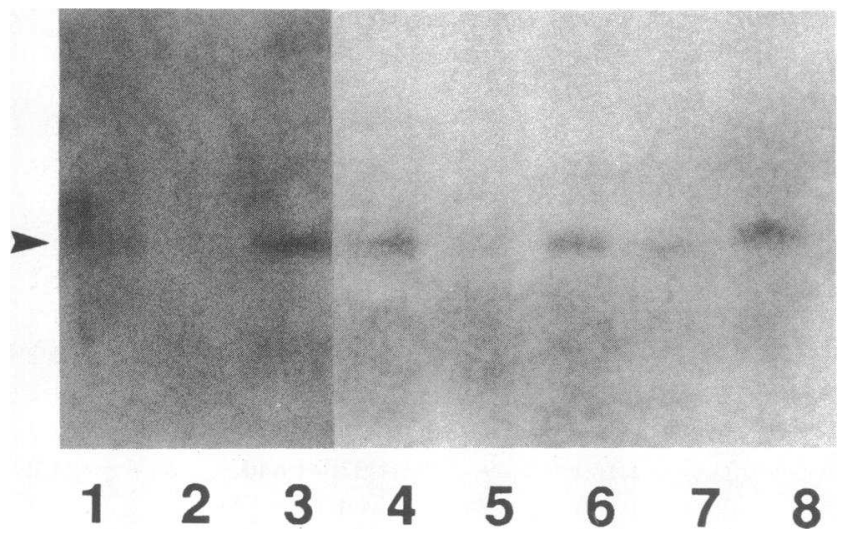

Figure 1. Portion of a Southern blot autoradiogram (prolonged exposure) showing an analysis for EBV nucleic acids using the EBV Bam $\mathrm{HI} \mathrm{W}$ probe and Bam $\mathrm{HI}$ restriction enzyme. Faint bands at $3 \mathrm{~kb}$ are seen in all lanes except lane 2 , indicating a low number of copies of EBV genomes in the peripheral blood lymphocytes of patients 1 and 3-8.

lymphocytes in seven cases and $7 \%$ of the lymphocytes in case 2. No aberrant expression of pan- $T$ cell antigens was noted, although the percentage of CD7 positive $T$ lymphocytes in cases 1 and 7 was somewhat lower than expected. The CD4 (helper) to CD8 (suppressor) ratios ranged from 0.11 to 0.86 . Although case 2 had a higher CD4:CD8 ratio and more B cells than other patients, this patient had no distinguishing clinical features.

EBV DNA was detected in seven cases (patients 1 and 3-8) by Southern blot analysis using the EBV Bam HI W probe (Fig. 1). The Southern blot autoradiogram from these seven patients revealed faint bands after prolonged exposure times, indicating a very low copy number of EBV genomes. There were no obvious hematologic, serologic, or immunologic differences between the seven positive cases and the negative case. EBV genome could not be detected in blood lymphocytes from any of the eight patients in Southern blot analysis using the less sensitive EBV terminal repeated sequence probe.

The results of the immunogenotype studies are summarized in Table III. A germline configuration was found for immunoglobulin heavy and light chain genes in all eight cases (data not shown). However, rearrangements of the beta and gamma TCR genes were detected in each patient. Using a $\mathbf{J}_{\gamma}$ probe with two separate restriction enzymes (Bgl II and Eco $\mathrm{RI}$ ), the blood from each patient showed several bands corresponding to the polyclonal rearrangement pattern previously described in the blood of normal individuals (30). Using $\mathbf{J}_{\beta 1+2}$ probes with two different restriction enzymes (Bgl III and Bam $\mathrm{HI}$ ), each case showed from 3 to $\sim 12$ bands of varying intensity and in different locations from case to case (Fig. 2). In addition, each case showed relative deletion of the $J_{\beta 1}$ germline band. For each case, an identical oligoclonal rearrangement pattern was obtained after hybridization of blots obtained by gel electrophoresis of two separate digests for each of the restriction enzymes used, minimizing the possibility that partial digestion of DNA contributed to the multiple band pattern. This pattern of oligoclonal rearrangements has not been observed in our previous studies using these restriction enzymes and probes $(12,31-34)$.

\section{Discussion}

Our study of the immunophenotype and EBV status of blood lymphocytes in acute EBV-IM patients agrees with observations in other studies. Previous studies have shown that CD8+ $T$ lymphocytes are the predominant cell type in the blood of EBV-IM patients (19), and these observations are confirmed in our series. Although previous reports have shown that EBVinfected B lymphocytes are found in the blood in low numbers (16), EBV genome was detected in the blood of seven of eight patients, using Southern blot analysis with the EBV Bam HI W probe. Since the EBV terminal repeated sequence probe is less sensitive than the Bam HI W probe, it is not surprising that we were not able to use this probe to assess the clonality of the EBV-infected lymphocytes, due to insufficient copies of EBV genome in the specimens. Polymerase chain reaction techniques would most likely demonstrate EBV genome in blood lymphocytes from all EBV-IM patients, but this technique also could potentially detect EBV in the blood of any patients previously exposed to Epstein-Barr virus.

The polyclonal pattern of gamma TCR rearrangements seen in our series has been previously described in the blood of normal individuals (30). The gamma TCR gene has only a small number of variable region segments, so that there is a very limited repertoire of potential rearrangements. Therefore, analysis of polyclonal $\mathrm{T}$ cell populations in normal patients may yield a set of nongermline bands corresponding to all of the potential rearrangements of this gene.

Table III. Summary of Immunogenotype Studies

\begin{tabular}{llllllll}
\hline & Case 1 & Case 2 & Case 3 & Case 4 & Case 5 & Case 6 & Case 7 \\
\hline $\mathbf{J}_{\mathbf{H}}($ Bam HI) & G & G & G & G & G & G & G \\
$\mathbf{J}_{\mathbf{H}}$ (Eco RI) & G & G & G & G & G & G & G \\
C $_{k}$ (Bam HI) & G & G & G & G & G & G & G \\
C $_{\lambda}$ (Eco RI) & G & G & G & G & G & G & G \\
$\mathbf{J}_{\gamma}$ (Bgl II) & PR & PR & PR & PR & PR & PR & PR \\
$\mathbf{J}_{\gamma}$ (Eco RI) & PR & PR & PR & PR & PR & PR & PR \\
$\mathbf{J}_{\beta 1+2}$ (Bgl II) & OR & OR & OR & OR & OR & OR & OR \\
$\mathbf{J}_{\beta 1+2}$ (Bam HI) & OR & OR & OR & OR & OR & OR & OR
\end{tabular}

G, germline; PR, polyclonal rearrangement pattern; OR, oligoclonal rearrangement pattern. 


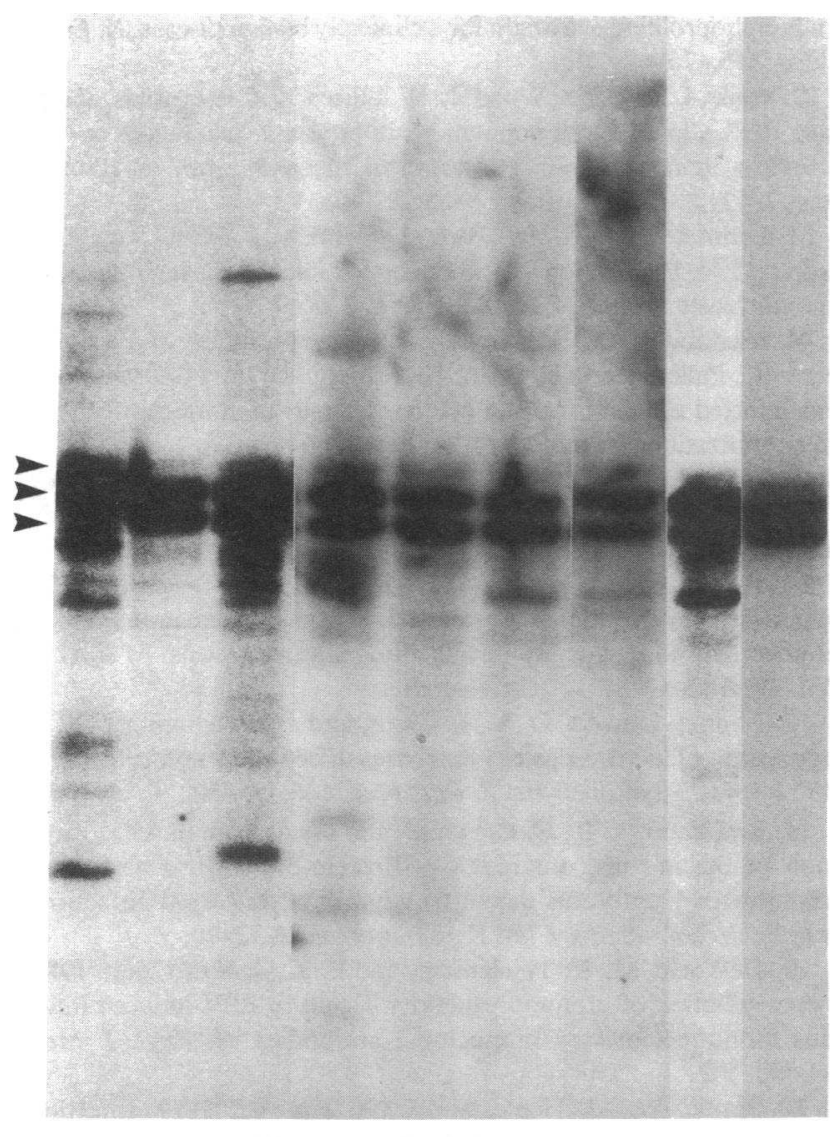

$\begin{array}{lllllllll}1 & 2 & 3 & 4 & 5 & 6 & 7 & 8 & \mathrm{C}\end{array}$

Figure 2. Composite autoradiogram, derived from two separate gels, showing analysis of the beta TCR gene using a $\mathrm{J}_{\beta 1+2}$ probe and $\mathrm{Bgl}$ II restriction enzyme. The background appears high because of the prolonged time of exposure $(9 \mathrm{~d})$. All lanes are loaded with the same amount of DNA. C represents a control peripheral blood specimen from a normal individual. Germline bands are designated by the arrows. All eight cases show from 3 to 12 extragermline bands of varying size and intensity. In addition, the $\mathrm{J}_{\beta 1}$ germline (at the upper arrow) is diminished in intensity compared to the lower two $\mathrm{J}_{\beta 2}$ germline bands. Patient 1 lacks the lower $\mathrm{J}_{\beta 2}$ germline band due to the absence of a polymorphism that is present in the DNA from the other patients.

The oligoclonal pattern of beta TCR gene rearrangements found in the blood of the patients in our series has not been previously reported in the blood or lymphoid tissues of patients with other benign or malignant $T$ cell populations. Since the large majority of malignant $T$ cell populations are thought to be monoclonal, arising from a single cell that has already undergone rearrangement of its TCR genes, each T cell in the clone usually has an identical beta TCR gene rearrangement. This results in the appearance of one or two nongermline rearrangement bands on Southern blot analysis (because either or both of two alleles may undergo rearrangement) (1-9). Three rearrangement bands have been reported to occur in several Southern blot analyses of two benign or indolent $\mathrm{T}$ cell lymphoproliferative disorders, lymphomatoid papulosis and pityriasis lichenoides et varioliformis acuta (Mucha-Habermann disease) (10-12). Although the appearance of three bands may be due to the presence of more than one clone of $T$ cells, other explanations include abnormal rearrangements, chromosomal hyperdiploidy, or somatic mutation of DNA of a previously rearranged gene in some fraction of the clonal cells in a monoclonal population. In contrast, most benign $\mathrm{T}$ cell populations are presumably polyclonal, with each clone of $\mathrm{T}$ cells having a unique beta TCR rearrangement. Since polyclonal T cell populations consist of enormous numbers of $T$ cell clones, each clone comprises only a very small portion of the population, so that no individual rearrangement band is large enough to be detectable by Southern blot analysis. However, relative or absolute deletion of the $J_{\beta 1}$ germline band is often seen because the $T$ cells are either rearranging their $J_{\beta 1}$ gene or deleting that gene and rearranging their $\mathrm{J}_{\beta 2}$ gene $(1-12)$.

In contrast to the patterns discussed above, our Southern blot analysis of the blood of EBV-IM patients revealed from 3 to about 12 beta TCR extragermline bands in every case. This most likely indicates that several clones of $\mathrm{T}$ cells are present, but many less than in the polyclonal populations of $\mathrm{T}$ cells present in most benign disorders. The rearrangement bands were of varying intensity and in different locations from case to case, indicating a unique oligoclonal pattern for each case. The relative deletion of the $J_{\beta 1}$ germline band also provides indirect evidence that the beta TCR genes in these T lymphocytes are undergoing rearrangement. An oligoclonal pattern of immunoglobulin gene rearrangements has been reported in hyperplastic lymph nodes from AIDS patients (35). However, a germline pattern was seen on analysis of the beta TCR gene in these cases. AIDS patients are known to have a predisposition to the development of B cell lymphoma, while individuals who have had acute EBV-IM have no known predisposition for $T$ cell lymphoma. Recently, one or two clonal populations of non-neoplastic $T$ cells have been described in a minority of patients with B cell chronic lymphocytic leukemia and multiple myeloma, found by performing Southern blotting studies on isolated $T$ cell populations (36).

It has been proposed that the T lymphocytes in the blood of patients of acute EBV-IM are important in containing the EBV infection and recovery of the patient. Since there is a lack of correlation between the appearance of humoral immunity and recovery from EBV-IM, attention has been focused on cell-mediated immune functions. In support of the hypothesis that cellular immunity is a prime mediator of recovery in these patients, T lymphocytes from EBV-IM patients have been shown to delay outgrowth of autologous EBV-infected B lymphocytes (17) and to inhibit outgrowth of EBV-transformed human fetal lymphocytes (18). Outgrowth inhibition can be demonstrated with either CD4+ or CD8 + T lymphocytes but is greatest when the effector $T$ cell population contains both CD4+ and CD8+ $T$ cells (37). Since cell-mediated immune mechanisms have been shown to be an important mechanism for recovery and immunity in many other viral infections, it is quite possible that this oligoclonal pattern of TCR gene rearrangements will not be found to be unique to patients with EBV-associated acute EBV-IM, but may also be encountered in other acute viral illnesses that are similarly studied.

In practical terms, this report has demonstrated the presence of oligoclonal TCR gene rearrangements in a benign and self-limited disease. Therefore, caution should be exercised in 
the evaluation of the blood of known or suspected lymphoma patients by gene rearrangement studies. The presence of extragermline bands alone should not be used to constitute evidence of malignant $T$ cell clone if the patient is suffering from an intercurrent illness that may be viral in nature. Although a unique pattern of 3 to 12 bands was observed in all eight cases reported here, it is likely that, at some point in each of these patients' courses, only one or two bands may have been detectable.

\section{Acknowledgments}

The authors thank Dr. Michael L. Cleary, in whose laboratory the gene rearrangement studies were performed. The blood samples were collected by Janet Schultz, M.T. Technical assistance for the immunophenotyping studies was provided by Mary Jane Kraft-Weisjahn, Karen Harris, Kay Kruel, Kim Schaper, Cindy Stanaway, Cathy Carollo-Neumann, and Diane Johnson. Carol Ghandour provided secretarial assistance.

\section{References}

1. Bertness, V., I. Kirsch, G. Hollis, B. Johnson, and P. A. Bunn. 1985. T-cell receptor gene rearrangements as clinical markers of human T-cell lymphomas. N. Engl. J. Med. 313:534-538.

2. Flug, F., P. G. Pelicci, F. Bonetti, D. M. Knowles, and R. DallaFavera. 1985. T-cell receptor gene rearrangements as markers of lineage and clonality in T-cell neoplasms. Proc. Natl. Acad. Sci. USA. 82:3460-3464.

3. Minden, M. D., B. Toyonaga, K. Ha, Y. Yanagi, B. Chin, E. Gelfand, and T. Mak. 1985. Somatic rearrangement of T-cell antigen receptor gene in human T-cell malignancies. Proc. Natl. Acad. Sci. USA. 82:1224-1227.

4. O'Connor, N. T. J., J. S. Wainscoat, D. J. Weatherall, K. C. Gatter, A. C. Feller, P. Isaacson, D. Jones, K. Lennert, G. Pallesen, A. Ramsey, et al. 1985. Rearrangement of the T-cell-receptor $\beta$-chain gene in the diagnosis of lymphoproliferative disorders. Lancet. i: $1295-1297$.

5. Sklar, J., and L. M. Weiss. 1988. Applications of antigen receptor gene rearrangements to the diagnosis and characterization of lymphoid neoplasms. Annu. Rev. Med. 39:315-334.

6. Waldmann, T. A., M. M. Davis, K. F. Bongiovanni, and S. J. Korsmeyer. 1985. Rearrangements of genes for the antigen receptor on $\mathrm{T}$ cells as markers of lineage and clonality in human lymphoid neoplasms. N. Engl. J. Med. 313:776-783.

7. Weiss, L. M., E. Hu, G. S. Wood, C. Moulds, M. L. Cleary, R. Warnke, and J. Sklar. 1985. Clonal rearrangements of T-cell receptor genes in mycosis fungoides and dermatopathic lymphadenopathy. $N$. Engl. J. Med. 313:539-544.

8. Weiss, L. M., G. S. Wood, E. Hu, E. A. Abel, R. T. Hoppe, and J. Sklar. 1989. Detection of clonal T-cell receptor gene rearrangements in the peripheral blood of patients with mycosis fungoides/Sezary syndrome. J. Invest. Dermatol. 92:601-604.

9. Weiss, L. M., and J. L. Sklar. 1990. T-cell neoplasms. In Molecular genetics in the diagnosis of cancer. J. Cossman, editor. Elsevier Science Publishers B. V., Amsterdam. 203-222.

10. Kadin, M. E., E. C. Vonderheid, D. Sako, L. K. Clayton, and S. Olbricht. 1987. Clonal composition of T cells in lymphomatoid papulosis. Am. J. Pathol. 126:13-17.

11. Weiss, L. M., G. S. Wood, M. Trela, R. A. Warnke, and J. Sklar. 1986. Clonal T-cell populations in lymphomatoid papulosis: evidence for a lymphoproliferative origin for a clinically benign disease. $N$. Engl. J. Med. 315:475-479.

12. Weiss, L. M., G. S. Wood, L. W. Ellisen, T. C. Reynolds, and J. Sklar. 1987. Clonal T-cell populations in pityriasis lichenoides et varioliformis acuta (Mucha-Habermann disease). Am. J. Pathol. 126:417-421.

13. Lemon, S. M., L. M. Hutt, J. E. Shaw, J. H. Li, and J. S. Pagano. 1977. Replication of EBV in epithelial cells during infectious mononucleosis. Nature (Lond.). 268:268-270.

14. Niedobitek, G., S. Hamilton-Dutoit, H. Herbst, T. Finn, M. Vetner, G. Pallesen, and H. Stein. 1989. Identification of Epstein-Barr virus-infected cells in tonsils of acute infectious mononucleosis by in situ hybridization. Hum. Pathol. 20:796-799.

15. Weiss, L. M., and L. A. Movahed. 1989. In situ demonstration of Epstein-Barr viral genomes in viral-associated B cell lymphoproliferations. Am. J. Pathol. 134:651-659.

16. Rocchi, G., A. de Felici, G. Ragona, and A. Heinz. 1977 Quantitative evaluation of Epstein-Barr-virus-infected mononuclear peripheral blood leukocytes in infectious mononucleosis. $N$. Engl. J. Med. 296:132-134.

17. Thorley-Lawson, D. A., L. Chess, and J. L. Strominger. 1977. Suppression of in vitro Epstein-Barr virus infection. A new role for the adult human T lymphocytes. J. Exp. Med. 146:495-508.

18. Rickinson, A. B., D. Crawford, and M. A. Epstein. 1977. Inhibition of the in vitro outgrowth of Epstein-Barr virus-transformed lymphocytes by thymus-dependent lymphocytes from infectious mononucleosis patients. Clin. Exp. Immunol. 28:72-79.

19. DeWaele, M., C. Thielemans, and B. K. G. Van Camp. 1981. Characterization of immunoregulatory T cells in EBV-induced infectious mononucleosis by monoclonal antibodies. N. Engl. J. Med. 304:460-462.

20. Henle, W., G. Henle, and C. A. Horwitz. 1979. Infectious mononucleosis and Epstein-Barr virus-associated malignancies. In Diagnostic Procedures for Viral, Rickettsial and Chlamydial Infections. 5th ed. E. H. Lennette, and N. J. Schmidt, editors. American Public Health Association, Inc., Washington, DC. 441-470.

21. Henle, W., G. E. Henle, and C. A. Horwitz. 1974. Epstein-Barr virus specific diagnostic tests in infectious mononucleosis. Hum. Pathol. 5:551-565.

22. Horwitz, C. A., W. Henle, G. Henle, H. Polesky, H. H. Balfour, Jr., R. A. Siem, S. Borken, and P. C. J. Ward. 1977. Heterophil-negative infectious mononucleosis and mononucleosis-like illnesses: laboratory confirmation of 43 cases. Am. J. Med. 63:947-957.

23. Lee, C. L., F. Zandrew, and I. Davidsohn. 1968. Horse agglutinins in infectious mononucleosis. III. Criterion for differential diagnosis. J. Clin. Pathol. (Lond.). 21:631-634.

24. Uckun, F. M., K. J. Gajl-Peczalska, J. H. Kersey, L. L. Houston, and D. A. Vallera. 1986. Use of a novel colony assay to evaluate the cytotoxicity of an immunotoxin containing pokeweed antiviral protein against blast progenitor cells freshly obtained from patients with common B-lineage acute lymphoblastic leukemia. J. Exp. Med. 163:347-368.

25. Cleary, M. L., J. Chao, R. Warnke, and J. Sklar. 1984. Immunoglobulin gene rearrangement as a diagnostic criterion of B-cell lymphoma. Proc. Natl. Acad. Sci. USA. 81:593-597.

26. Southern, E. M. 1975. Detection of specific sequences among DNA fragments separated by gel electrophoresis. J. Mol. Biol. 98:503-517.

27. Feinberg, A. P., and B. Vogelstein. 1983. A technique for radiolabeling DNA restriction endonuclease fragments to high specific activity. Anal. Biochem. 132:6-13.

28. Cheung, A., and E. Kieff. 1982. Long internal direct repeat in Epstein-Barr virus DNA. J. Virol. 44:286-294.

29. Raab-Traub, N., and K. Flynn. 1986. The structure of the termini of the Epstein-Barr virus as a marker of clonal cellular proliferation. Cell. 47:883-889. 
30. Uppenkamp, M., S. Pittaluga, E. H. Lipford, and J. Cossman. 1987. Limited diversity and selection of rearranged $\gamma$ genes in polyclonal T cells. J. Immunol. 138:1618-1620.

31. Weiss, L. M., L. J. Picker, T. M. Grogan, R. A. Warnke, and J. Sklar. 1988. Absence of clonal beta and gamma T-cell receptor gene rearrangements in a subset of peripheral T-cell lymphomas. Am. J. Pathol. 130:436-442.

32. Weiss, L. M., L. J. Picker, C. M. Copenhaver, R. A. Warnke, and J. Sklar. 1988. Large-cell hematolymphoid neoplasms of uncertain lineage. Hum. Pathol. 19:967-973.

33. Weiss, L. M., G. S. Wood, E. Hu, E. A. Abel, R. T. Hoppe, and J. Sklar. 1989. Detection of clonal T-cell receptor gene rearrangements in the peripheral blood of patients with mycosis fungoides/Sezary syndrome. J. Invest. Dermatol. 92:601-604.

34. Wood, G. S., L. M. Weiss, C. H. Hu, E. A. Abel, R. T. Hoppe,
R. A. Warnke, and J. Sklar. 1988. T-cell antigen deficiencies and clonal rearrangements of T-cell receptor genes in pagetoid reticulosis (Woringer-Kolopp diease). N. Engl. J. Med. 318:164-167.

35. Pelicci, P. G., D. M. Knowles, Z. A. Arlin, R. Wieczorek, P. Luciw, D. Dina, C. Basilico, and R. Dalla-Favera. 1986. Multiple monoclonal $\mathrm{B}$ cell expansions and $\mathrm{c}-\mathrm{myc}$ oncogene rearrangements in acquired immune deficiency syndrome-related lymphoproliferative disorders. Implications for lymphomagenesis. J. Exp. Med. 164:20492060.

36. Wen, T., H. Mellstedt, and M. Jondal. 1990. Presence of clonal $\mathrm{T}$ cell populations in chronic B lymphocytic leukemia and smouldering myeloma. J. Exp. Med. 171:659-666.

37. Schooley, R. T., D. I. Arbit, W. Henle, and M. S. Hirsch. 1984. T-lymphocyte subset interactions in the cell-mediated immune response to Epstein-Barr virus. Cell. Immunol. 86:402-412. 